DOI: 10.25557/0031-2991.2021.03.42-47

(с) Коллектив авторов, 2021

уДК 616-092.9+612.841.1

Панов А.А., Ржавина Е.М., Морозова М.П., Ердяков А.К., Гаврилова С.А.

Влияние длительной гипергликемии на морфологию роговицы и сетчатки у крыс при стрептозотоцин-индуцированном сахарном диабете

ФГБОУ ВО «Московский государственный университет им. М.В. Ломоносова», 119991, Москва, Россия, Ломоносовский проспект, д. 27, корп. 1

Цель исследования - изучение динамики морфологических изменений роговицы и заднего отдела глаза крыс при длительной гипергликемии.

Методика. Исследование выполнено на 36 самцах крыс Wistar. Сахарный диабет индуцировали внутрибрюшинной инъекцией стрептозотоцина (65 мг/кг), после чего ежедневно вводили подкожно малые дозы инсулина (2 ЕД/кг). На 50-е, 58-е и 66-е сут эксперимента производили энуклеацию глаз у глубоко наркотизированных животных. Гистологические срезы фрагментов глаз окрашивали гематоксилин-эозином, проводили морфометрию параметров роговицы и сетчатки.

Результаты. Средняя концентрация глюкозы и кетоновых тел крови в группе сахарного диабета составила 29,8 ммоль/л и 0,889 ммоль/л, в контрольной группе - 6,2 ммоль/л и 0,847 ммоль/л соответственно. Анализ гистологических срезов глаз выявил признаки отека роговицы, хориоидеи и наружных слоев центральных отделов сетчатки до появления других качественных и количественных морфологических изменений.

Заключение. Оценка толщины роговицы, хориоидеи и наружных слоев центральных отделов сетчатки может служить предиктором развития диабетической ретинопатии.

Ключевые слова: гипергликемия; сахарный диабет; диабетическая ретинопатия; роговица; хориоидея; сетчатка

Для цитирования: Панов А.А., Ржавина Е.М., Морозова М.П., Ердяков А.К., Гаврилова С.А. Влияние стрептозотоцин-индуцированного сахарного диабета на морфологию роговицы и сетчатки у крыс. Патологическая физиология и экспериментальная терапия. 2021; 65(3): 42-47.

DOI: $10.25557 / 0031-2991.2021 .03 .42-47$

\begin{abstract}
Участие авторов: концепция и дизайн исследования - Гаврилова С.А.; сбор материала - Ржавина Е.М., Морозова М.П., Ердяков А.К., Панов А.А.; анализ и интерпретация данных - Панов А.А., Ржавина Е.М. Ердяков А.К.; статистическая обработка данных - Панов А.А., Ржавина Е.М., Ердяков А.К.; подготовка иллюстративного материала - Панов А.А.; написание текста - Панов А.А., Ердяков А.К., Гаврилова С.А., редактирование текста - Ердяков А.К., Гаврилова С.А.; обсуждение окончательной версии статьи - Панов А.А., Ердяков А.К., Гаврилова С.А.
\end{abstract}

Для корреспонденции: Гаврилова Светлана Анатольевна, e-mail: sgavrilova@mail.ru

Финансирование. Работа поддержана грантом РНФ 16-15-10365 «Нейрогуморальная регуляция репарации тканей при сахарном диабете».

Конфликт интересов. Авторы заявляют об отсутствии конфликта интересов.

Поступила 28.05.2021

Принята к печати 30.06.2021

Опубликована 30.09.2021

Panov A.A., Rzhavina E.M., Morozova M.P., Erdiakov A.K., Gavrilova S.A.

\title{
Effect of long-term hyperglycemia on cornea and retina morphology in rats with streptozotocin-induced diabetes mellitus
}

M.V. Lomonosov Moscow State University,

Lomonosovsky Prospekt 27, Bld. 1, Moscow 119991, Russian Federation

The aim was to study morphological changes in the cornea and the posterior part of rat eye during prolonged hyperglycemia. Methods. The study was performed on 36 Wistar male rats. Diabetes mellitus was induced by an injection of streptozotocin (65 $\mathrm{mg} / \mathrm{kg}$, i.p.) followed by daily injections of low doses of insulin ( $2 \mathrm{U} / \mathrm{kg}$, s.c.). Eyes were enucleated from deeply anesthetized rats on days 50,58, and 66 of the experiment. Histologic sections were stained with hematoxylin-eosin, and morphometry of the cornea and the retina was performed.

Results. Mean blood concentrations of glucose and ketone bodies were $29.8 \mathrm{mmol} / \mathrm{L}$ and $0.889 \mathrm{mmol} / \mathrm{L}$, respectively, in the diabetic group and $6.2 \mathrm{mmol} / \mathrm{L}$ and $0.847 \mathrm{mmol} / \mathrm{L}$, respectively, in the control group. The histological analysis revealed signs of edema 
DOI: 10.25557/0031-2991.2021.03.42-47

in the cornea, choroid and outer layers of the central retina, which preceded other morphological changes.

Conclusion. Evaluating thickness of the cornea, choroid and outer layers of the central retina may serve for prediction of diabetic retinopathy.

Keywords: hyperglycemia; diabetes mellitus; diabetic retinopathy; cornea; choroid; retina

For citation: Panov A.A., Rzhavina E.M., Morozova M.P., Erdiakov A.K., Gavrilova S.A. Features of the morphology of the cornea and retina in rats with streptozotocin-induced diabetes mellitus. Patologicheskaya Fiziologiya i Eksperimental naya terapiya. (Pathological Physiology and Experimental Therapy, Russian Journal). 2021; 65(3): 42-47.

DOI: $10.25557 / 0031-2991.2021 .03 .42-47$

\begin{abstract}
Contribution: concept and design of the study - Gavrilova S.A.; collection of material - Rzhavina E.M., Morozova M.P., Erdiakov A.K., Panov A.A.; data analysis and interpretation - Panov A.A., Rzhavina E.M. Erdiakov A.K.; statistical analysis - Panov A.A., Rzhavina E.M. Erdiakov A.K..; preparation of illustrative material - Panov A.A.; text writing - Panov A.A., Erdiakov A.K., Gavrilova S.A.; text editing - Erdiakov A.K., Gavrilova S.A.; critique of the final version of the manuscript - Panov A.A., Erdiakov A.K., Gavrilova S.A.
\end{abstract}

For correspondence: Svetlana A. Gavrilova, Doctor of Biological Sciences, Associate Prof., Department of Physiology and General Pathology, Faculty of Medicine, Lomonosov Moscow State University, e-mail: sgavrilova@mail.ru

Financing. Grant RSF 16-15-10365 "Neurohumoral regulation of tissue repair in diabetes mellitus".

Conflict of interest. The authors declare no conflict of interest.

Information about the authors:

Morozova M.P., https://orcid.org/0000-0002-7829-4753

Erdiakov A.K., https://orcid.org/0000-0002-2208-5733

Gavrilova S.A., https://orcid.org/0000-0002-8776-6062

Received: 28.05.2021

Accepted: 30.06 .2021

Published: 30.09 .2021

\section{Введение}

Диабетическая ретинопатия - распространенное микрососудистое осложнение сахарного диабета (СД), которое является ведущей причиной потери зрения в развитых странах [1]. Для диагностики этого заболевания у людей проводят обследование глазного дна и сосудов сетчатки с помощью фундоскопии, оптической когерентной томографии и ангиографии [2]. Выраженность изменений коррелирует с длительностью СД [3], однако нередко тяжелая ретинопатия с необратимыми изменениями выявляется у пациентов с недавно диагностированным СД уже при первом скрининге [4]. В связи с этим, актуальным является изучение влияния стойкой гипергликемии на патологические изменения в органе зрения на различных животных моделях, а также определение механизмов и динамики развития повреждения сетчатки и роговицы при СД. Выявление ранних морфологических изменений, развивающихся на фоне гипергликемии, поможет выявить предикторы развития диабетической ретинопатии. В связи с этим, целью работы стало изучение динамики морфологических изменений, происходящих в заднем отрезке глаза и роговице при длительной гипергликемии в стрептозотоцин-индуцированной модели СД у крыс.

\section{Методика}

Животных содержали в соответствии с ГОСТ $33216-$ 2014 «Руководство по содержанию и уходу за лабора- торными животными. Правила содержания и ухода за лабораторными грызунами и кроликами». На проведение опытов получено разрешение комиссии по биоэтике факультета фундаментальной медицины МГУ им. М.В. Ломоносова: №БМЭ-12-17/-03 от 19.09.2017.

Исследование выполнено на 36 самцах крыс Wistar массой 400-450 г. Животных содержали в условиях вивария в режиме 12 ч день/12 ч ночь, со свободным доступом к воде и корму (комбикорм для разведения грызунов, ООО «Лабораторкорм»). Крысы были рандомизированы на 3 группы: СД (сахарный диабет) $(n=18)-$ внутрибрюшинная инъекция раствора стрептозотоцина (65 мг/кг) в цитратном буфере 5 мМ $(\mathrm{pH} 4,5)$ для моделирования сахарного диабета; ЦБ (цитратный буфер) $(n=14)$ - внутрибрюшинная инъекция цитратного буфера 5 мМ (pH 4,5), растворителя стрептозотоцина; ИК $(n=4)$ - интактный контроль (без воздействий). Через трое суток после соответствующих инъекций у всех крыс определяли уровень глюкозы в капиллярной крови и из эксперимента исключали животных из группы СД с концентрацией глюкозы менее 15 мМ. Этот день считали 1-м днем эксперимента. Для увеличения выживаемости крысам группы СД каждое утро выполняли инъекцию инсулина (2 ЕД/кг) подкожно. Всех крыс ежедневно взвешивали, раз в неделю измеряли концентрацию глюкозы (глюкометры OneTouch Verio, Johnson\&Johnson- для групп ЦБ, ИК и iCheck, 
DOI: 10.25557/0031-2991.2021.03.42-47

Diamedical - для группы СД) и кетоновых тел (кетометр Optium Xceed, Abbott) в капиллярной крови из кончика хвоста. Прокол выполняли скарификатором, депривацию воды и корма не проводили.

Энуклеацию глаз выполняли у глубоко наркотизированных хлоралгидратом крыс на 50-е, 58-е и 66е сут эксперимента с учетом особенностей развития диабета у крыс. Затем добавляли наркоз до остановки сердца. Глаза помещали в фиксатор Дэвидсона на 16 ч и после стандартных принятых в гистологии процедур заливали в парафин. Глаз при процедуре заливки ориентировали в блоке так, чтобы срезы проходили через задний полюс и роговицу параллельно продольной оси глаза (рис. 1). Срезы толщиной 5 мкм окрашивали гематоксилин-эозином. Морфометрию осуществляли на срезе в двух зонах: вблизи продольной оси глаза (центр) и ближе к цилиарному телу (периферия) (рис. 1).

Морфологический анализ проводили с помощью светового микроскопа Zeiss Axio Imager A2. Общую морфологию оценивали при ув. 200. В роговице изучали прилегание клеток переднего эпителия друг к другу, оценивали прямолинейный или волнообразный ход десцеметовой мембраны, в заднем отрезке глаза - наличие мягких экссудатов (зон локальных утолщений слоя ганглиозных клеток и нервных волокон) и твердых экссудатов (массивных скоплений эозинофильного материала в плексиформных слоях), отмечали также наличие кровоизлияний, новообразованных сосудов и эпиретинальных мембран. Морфометрию проводили при ув. 400. Расчеты выполняли в программe ZeissZEN 2.6 blue edition (CarlZeiss Microscopy Gm$\mathrm{bH}$, Германия). В роговице измеряли толщину слоев: переднего эпителия, боуменовой мембраны, стромы, десцеметовой мембраны и эндотелия роговицы; в заднем отрезке глаза - толщину слоев: нервных волокон

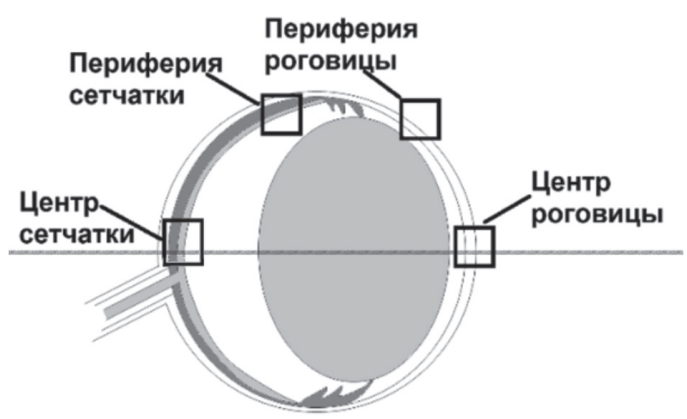

Рис. 1. Зоны измерения показателей на гистологических срезах глаз крыс. Серой прямой обозначена продольная ось глазного яблока.

Fig. 1. Zones of measurement on histological sections of rat eyes. The gray line marks the longitudinal axis of the eyeball. и ганглиозных клеток, внутреннего плексиформного, внутреннего ядерного, наружного плексиформного, наружного ядерного, слоя фоторецепторов, пигментного эпителия, хориоидеи - а также подсчитывали количество рядов ядер в наружном ядерном слое и слое ганглиозных клеток.

Статистический анализ выполняли в программе STATISTICA 8.0. Нормальность распределения оценивали с помощью критериев Колмогорова-Смирнова и Шапиро-Уилка. Использовали непараметрический U-критерий Манна-Уитни для оценки межгрупповых различий, критерий Вилкоксона для сравнения показателей внутри одной группы в разные периоды времени и критерий Краскела-Уоллиса для анализа динамики изменения показателей. Статистически значимыми считали различия при $p<0,05$. При сравнении групп ЦБ и ИК по всем показателям не выявлено статистически значимых различий, поэтому при анализе эти группы были объединены в одну контрольную (К). Данные представлены в виде медианы, первого и третьего квартиля - Me (Q1; Q3) или среднего \pm стандартное отклонение $(\mathrm{M} \pm \mathrm{SD})$.

\section{Результаты и обсуждение}

Инсулинотерапия крыс в группе СД в дозе 2 ЕД/кг не снижала высокую концентрацию глюкозы в крови, но предотвращала гибель животных. В группе СД c 1-х сут эксперимента наблюдали статистически значимое увеличение среднего уровня глюкозы крови (СД 29,8 $\pm 12,7$ мМ, по сравнению с контролем (К группа) $6,2 \pm 1,4$ мM, $p<0,0005)$. С 35 -х сут отмечалось статистически значимое $(p<0,0001)$ снижение средней мас-

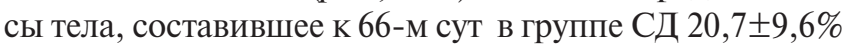
по сравнению с массой в

1-е сут эксперимента. В группе К масса тела крыс в течение эксперимента статистически значимо не изменилась. Уровень кетоновых тел в группе СД не изменился (СД 0,889 $\pm 0,541 \mathrm{мМ,} \mathrm{по} \mathrm{сравнению}$ с K $0,847 \pm 0,217$ мМ, $p=0,46)$. Таким образом, в эксперименте получена модель гипергликемии без кетоацидоза.

При световой микроскопии срезов роговицы в группе СД выявлены качественные морфологические изменения: неплотное прилегание эпителиальных клеток друг к другу (рис. 2, Б), в некоторых случаях с формированием значительных эпителиальных дефектов (рис. 2, В), причем данные изменения в группе K не обнаружены. (рис. 2, А). В группе СД на всех сроках наблюдения отмечалась волнообразная складчатость десцеметовой мембраны (рис. 2, В), в группе К подобные изменения отсутствовали. 
Выявлены также количественные изменения морфометрических параметров роговицы в группе СД: обнаружено статистически значимое увеличение общей толщины роговицы и толщины ее стромы в центре и на периферии, утолщение десцеметовой мембраны и эндотелия роговицы в центре по сравнению с группой К (табл. 1).

По данным Cameron и соавторов (2001), существует положительная корреляция между концентрациями глюкозы в водянистой влаге и в плазме [5]. Избыток глюкозы приводит к повреждению клеток эндотелия роговицы, которые в норме обеспечивают дегидратацию ее стромы [6]. Из-за снижения насосной функции эндотелия происходит отек роговицы, что проявляется в увеличении толщины ее стромы, складчатости десцеметовой мембраны [7] и не- плотном прилегании клеток переднего эпителия друг к другу [8]. Это согласуется с результатами нашего эксперимента.

При анализе срезов заднего отрезка глаза не выявлено качественных морфологических различий между группами СД и К: в обеих группах мягкие и твердые экссудаты, кровоизлияния, патологические новообразованные сосуды, эпиретинальные мембраны не обнаружены (рис. 3).

Количественные различия показателей между двумя группами включали статистически значимое увеличение толщины хориоидеи: в центре в 1,26 раз, на периферии в 1,58 раз. Толщина наружных слоев в центре сетчатки у крыс группы СД увеличилась в 1,16 раз. Также в группе СД отмечена тенденция к увеличению общей толщины сетчатки в центре (табл. 2).
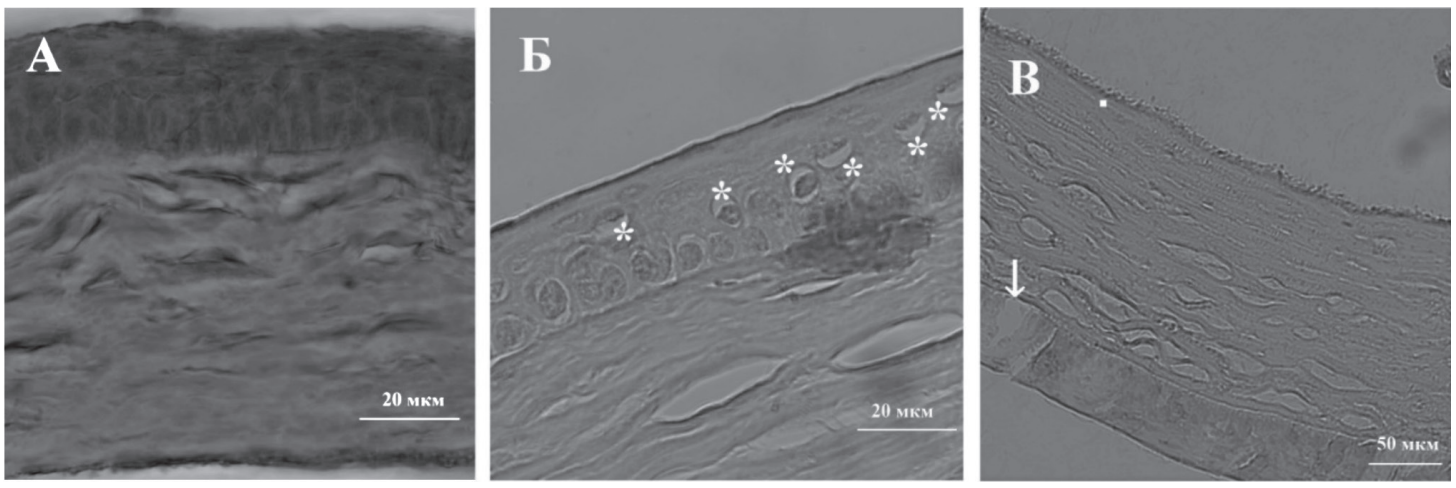

Рис. 2. Морфологические изменения эпителия роговицы, окраска гематоксилин-эозином. А. Группа К, ув. 400. Межклеточный отек отсутствует, эпителиальные клетки плотно прилежат друг к другу. Б. Группа СД, ув. 400. * - неплотное прилегание клеток эпителия роговицы друг к другу. В. Роговица крысы из группы СД, ув. 200. $\square$ - умеренно выраженная волнообразная складчатость десцеметовой мембраны и эндотелия роговицы. $\downarrow$ - дефекты в переднем эпителии роговицы.

Fig. 2. Morphological changes in the corneal epithelium stained with hematoxylin-eosin. A. Control group, magnification $400 x$. Intercellular edema is absent, epithelial cells are tightly adjacent to each other. B. Group with diabetes mellitus (DM), magnification 400x. *loose fit of corneal epithelial cells to each other. C. The cornea of a rat from the DM group, magnification 200x. $\square$ moderately pronounced wavy folding of the Descemet's membrane and the corneal endothelium. $\downarrow$ defects in the anterior corneal epithelium.

Таблица 1/Table 1

Изменение толщины роговицы и отдельных ее слоев в группе СД по сравнению с контрольной группой Changes in the thickness of the cornea and its individual layers in the DM group in comparison with the control group

\begin{tabular}{||l|c|c|c||}
\hline \multicolumn{1}{|c|}{ Показатель } & Сахарный диабет, мкм & Контроль, мкм & \multicolumn{1}{|c||}{ р } \\
\hline Общая толщина роговицы в центре & $150,5(130,4 ; 187,3)$ & $125,1(103,3 ; 149,1)$ & 0,0018 \\
\hline Общая толщина роговицы на периферии & $158,7(139,6 ; 170,3)$ & $120,6(91,4 ; 144,2)$ & 0,00007 \\
\hline Толщина стромы в центре & $104,3(80,9 ; 138,1)$ & $77,2(63,2 ; 106,3)$ & 0,003 \\
\hline Толщина стромы на периферии & $119(95,7 ; 132,6)$ & $82,6(60,8 ; 96,3)$ & 0,00003 \\
\hline Толщина десцеметовой мембраны и эндотелия роговицы в центре & $6,7(4,6 ; 9,7)$ & $4,9(3,6 ; 6,3)$ & 0,006 \\
\hline
\end{tabular}

Примечание. Различия в показателях толщины других слоев роговицы не были статистически значимы.

Note. Differences in the thickness of other corneal layers were not statistically significant. 


\section{DOI: 10.25557/0031-2991.2021.03.42-47}

Анализ динамики изменения показателей в группе СД не выявил значимых различий между сроками развития СД, что говорит о том, что вышеописанные изменения появились раньше, до 50-х сут эксперимента.

Так, по данным Joussen и соавторов (2002), при гипергликемии лейкоциты имеют повышенную экспрессию CD18 - рецептора для молекулы клеточной адгезии ICAM-1 [9]. При этом в эндотелии хориоидеи увеличивается экспрессия ICAM-1 [10]. В результате лейкоциты «застревают» в просвете сосудов хориоидеи и повреждают эндотелиоциты активными формами кислорода АФК [10]. Это приводит к гибели клеток эндотелия, увеличению сосудистой проницаемости и отеку хориоидеи [11]. Лейкостаз в сосудах при гипергликемии развивается уже через одну неделю после индукции СД [11] и сохраняется длительное время [12]. Увеличение толщины наружных слоев сетчатки в центре можно объяснить распространением отека с хориоидеи на эти слои.

\section{Заключение}

Таким образом, в полученной модели изолированной гипергликемии (без кетоацидоза) при стрептозотоцин-индуцированном СД обнаружены признаки отека роговицы, хориоидеи и наружных слоев центральных отделов сетчатки в группе СД, которые развиваются на ранних сроках эксперимента (еще до 50-х сут), но в остальном морфология сетчатки в группе СД на всех исследуемых сроках не отличалась от таковой в группе К. Вероятно, в условиях длительной гипергликемии эти изменения являются наиболее ранними, поэтому измерение толщины выше-
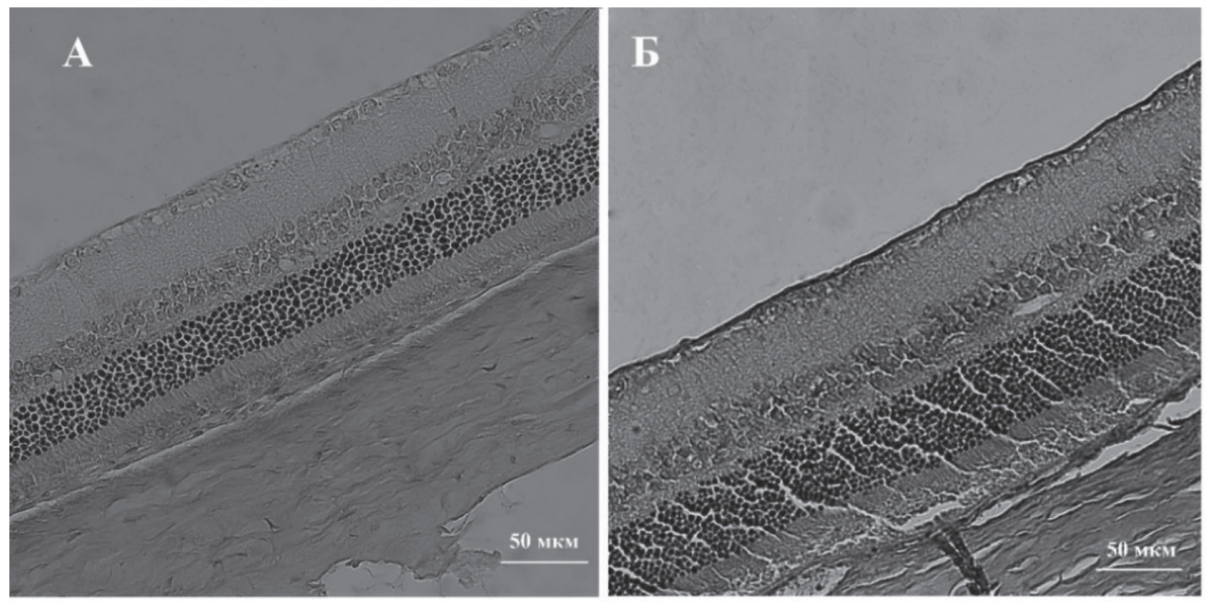

Рис. 3. Общий вид гистологических срезов сетчатки крыс (центральная часть), окраска гематоксилин-эозином, ув. 200. А. Группа К. Б. Группа СД. Отмечается утолщение наружных слоев сетчатки по сравнению с контролем.

Fig. 3. General view of histological sections of the rat retina (central part) stained with hematoxylin-eosin, magnification $\times 200$. A. Control group. B. DM group. Outer layers of the retina are thickened compared to the control group.

Изменения показателей заднего отрезка глаза в группе СД по сравнению с контрольной группой Changes in the parameters of the posterior segment of the eye in the DM group as compared with the control group

\begin{tabular}{||l|c|c|c||}
\hline \hline \multicolumn{1}{|c|}{ Показатель } & Сахарный диабет, мкм & Контроль, мкм & р \\
\hline Толщина хориоидеи в центре & $23,6(18,5 ; 31,5)$ & $18,7(14,6 ; 24,6)$ & 0,019 \\
\hline Толщина хориоидеи на периферии & $19(13,4 ; 23,5)$ & $12(9,3 ; 15,9)$ & 0,0003 \\
\hline Толщина наружных слоев сетчатки & $85,8(65,6 ; 97,3)$ & $73,7(60,9 ; 80,7)$ & 0,049 \\
\hline Общая толщина сетчатки в центре & $144,7(110,2 ; 166,2)$ & $116,6(99,1 ; 132)$ & 0,064 \\
\hline
\end{tabular}

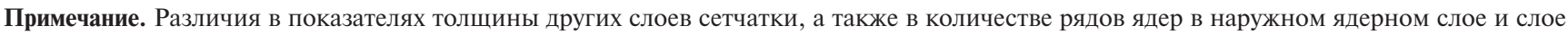
ганглиозных клеток между двумя группами не были статистически значимы.

Note. Differences in thickness of other retinal layers and in the number of rows of nuclei in the outer nuclear layer and the ganglionic cell layer between the groups were not statistically significant. 
указанных зон может служить предиктором развития диабетической ретинопатии. Целесообразно проведение повторной серии экспериментов с изучением развития диабетической ретинопатии у крыс на более ранних сроках (до 50-х сут).

\section{Литература/References}

1. Hendrick A.M., Gibson M.V., Kulshreshtha A. Diabetic Retinopathy. Prim. Care. 2015; 42(3): 451-64. doi: 10.1016/j.pop. 2015.05.005

2. Safi H., Safi S., Hafezi-moghadam A., Ahmadieh H. Early detection of diabetic retinopathy. Surv. Ophthalmol. 2018; 63(5): 601-8. doi: 10.1016/j.survophthal.2018.04.003

3. Correa Z.M., Freitas A.M., Marcon I.M. Risk factors related to the severity of diabetic retinopathy. Arq. Bras. Oftalmol. 2003; 66(6): 73943. doi: $10.1590 /$ S0004-27492003000700002

4. Hammes H.P. Diabetic retinopathy: hyperglycaemia, oxidative stress and beyond. Diabetologia. 2018; 61(1): 29-38. doi: 10.1007/s00125$017-4435-8$

5. Cameron B.D., Baba J.S., Coté G.L. Measurement of the glucose transport time delay between the blood and aqueous humor of the eye for the eventual development of a noninva- sive glucose sensor. Diabetes Technol. Ther. 2001; 3(2): 201-7. doi: 10.1089/152091501300209552

6. Zhao H., He Y., Ren Y.R., Chen B.H. Corneal alteration and pathogenesis in diabetes mellitus. Int. J. Ophthalmol. 2019; 12(12): 193950. doi: 10.18240/ijo.2019.12.17

7. Delmonte D.W., Kim T. Anatomy and physiology of the cornea. J. Cataract. Refract. Surg. 2011; 37(3): 588-98. doi: 10.1016/j. jers.2010.12.037

8. Edelhauser H.F. The Balance between Corneal Transparency and Edema: The Proctor Lecture. Invest. Ophthalmol. Vis. Sci. 2006; 47(5): 1755-67. doi: 10.1167/iovs.05-1139

9. Joussen A.M., Poulaki V., Mitsiades N., Kirchhof B., Koizumi K., Döhmen S., et al. Nonsteroidal anti-inflammatory drugs prevent early diabetic retinopathy via TNF-alpha suppression. FASEB J. 2002; 16(3): 438-40. doi: 10.1096/fj.01-0707fje

10. Lutty G.A. Effects of Diabetes on the Eye. Invest. Ophthalmol. Vis. Sci. 2013; 54(14): 81-7. doi: 10.1167/iovs.13-12979

11. Joussen A.M., Murata T., Tsujikawa A., Kirchhof B. Leukocyte-Mediated Endothelial Cell Injury and Death in the Diabetic Retina. Am. J. Pathol. 2001; 158(1): 147-52. doi: 10.1016/S0002-9440(10)63952-1

12. Joussen A.M., Poulaki V., Le M.L., Koizumi K., Esser C., Janicki H., et al. A central role for inflammation in the pathogenesis of diabetic retinopathy. FASEB J. 2004; 18(12): 1450-2. doi: 10.1096/fj.03-1476fje

\section{Сведения об авторах:}

Панов Андрей Алексеевии, студент факультета фундаментальной медицины МГУ им. М.В. Ломоносова;

Ржавина Екатерина Михайловна, канд. биол. наук, науч. сотр. факультета фундаментальной медицины МГУ им. М.В. Ломоносова;

Морозова Мария Павловна, канд. биол. наук, доцент каф. физиологии и общей патологии факультета фундаментальной медицины МГУ им. М.В. Ломоносова;

Ердяков Алексей Константинович, канд. биол. наук, ст. науч. сотр. Межфакультетской научно-исследовательской лаборатории трансляционной медицины факультета фундаментальной медицины МГУ им. М.В. Ломоносова;

Гаврилова Светлана Анатольевна, доктор биол. наук, доцент каф. физиологии и общей патологии факультета фундаментальной медицины МГУ им. М.В. Ломоносова, e-mail: sgavrilova@mail.ru 